\title{
A Comparative Assessment of Material Use in Three Medical
}

\section{Libraries in Sri Lanka}

\author{
D.T. Peterson ${ }^{1}$ \\ BSc, MSc Zoology (Pune), MLS (Colombo) \\ Sumana Jayasuriya ${ }^{2}$ \\ BA (Hons), PG Dip in LIS(Sri Lanka), MLS (Phillippines), Hon Fellow SLLA
}

\begin{abstract}
Assessing the use of library materials justifies the extent the library fulfills its main objective of providing information to its users. Furthermore, assessing the use of library materials is considered as a method of measuring library performance. The objective of this study was to find the usage of library collections held by the medical libraries of University of Colombo, Kelaniya and Sri Jayewardenepura and to recommend measures that could be taken to enhance their collection use. Suitable indicators to assess collection use were selected from performance indicators developed by the International Federation of Library Associations and Institutions (IFLA), International Organization for Standardization (ISO), and American Library Association (ALA). The collection use was assessed following the methodologies given for each indicator. Results showed that the Medical library of University of Kelaniya had the highest usage of the collection, followed by the Medical library of University of Colombo and the Medical library of University of Sri Jayawardenepura. The analysis of library services, loans and acquisitions policies of the three libraries showed that the quality and quantity of the library collection, library opening hours, loans policy and seating capacity within the library affect the use of the library's collection. It can be recommended from this study that amending its loans policy to allow borrowing of two lending books at a time per user at the Medical library of University of Colombo and amending its collection development policy at Medical Library of University of Sri Jayewardenepura would result in higher use of library materials.
\end{abstract}

\footnotetext{
${ }^{1}$ Assistant Librarian, University of Sri Jayewardenepura.

Email: dimuthu@sjp.ac.lk ${ }^{2}$ Librarian, University of Colombo

E-mail: sumanaj@lib.cmb.ac.lk
} 
The Medical libraries of Kelaniya and Sri Jayewardenepura should consider increasing opening hours. All three libraries assessed should adopt suitable weeding policies in order to maintain up to date collections.

Key words: Collection use, Performance measurement, Medical libraries

\section{Introduction}

The main objective of any library is to provide information material to its users. For years, libraries have been providing information resources to users, without assessing how good the collection is or how well the collection has been used. The substantial amount of money spent on collection development is justified only if the materials are used by its target population. Assessing library collection use has become important, especially with easy access to information through internet and restrictions in budget to acquire materials. Assessing the use of library materials reveals the quality and quantity of the collection.

Assessing the use of library materials is considered as a method of measuring library performance. According to ISO standard 11620, Performance is the 'effectiveness of the provision of services by the library and the efficiency of the allocation and use of resources in providing services' (ISO 11620, 1998). Library performance can be measured using performance indicators that are defined as, 'numerical, symbolic or verbal expression, derived from library statistics and data used to characterize the performance of a library' (ISO 11620, 1998). Many indicators have been developed internationally to measure library performance, among which are indicators to measure collection use. 


\section{Background to Study}

Libraries of Faculties of Medicine of University of Colombo (UCFM), University of Kelaniya (UKFM) and University of Sri Jayewardenepura (SJPFM) were selected for this study. These three different libraries were with different sizes of collections, library space, loan policies and acquisition policies.

Out of the three Medical libraries, that of the University of Colombo is the oldest, with a history dating back more than a century (University of Colombo, 2008). It is located separately from the main university premises. The long history has contributed to result in a well established library with a comparably large collection, but has the drawback of limitation of space with only $149.4 \mathrm{~m}^{2}$ of space available for users. It consists of a collection of about 17,500 monographs (University of Colombo, 2008). In addition, it consists of a considerably large collection of medical books published locally. Periodicals are held in a separate section of the library. The library remains open from 8.30 a.m. to 8 p.m. all days, including weekends and public holidays, except on special holidays. The Medical library of University of Colombo caters to about 1550 students and 125 academic staff members currently.

The library of the Medical Faculty, University of Kelaniya was founded in 1981 as the Library of the North Colombo Medical College (NCMC), which became the Medical Library of the University of Kelaniya in 1991. It is located separately from the main university premises. It has inherited a book collection consisting of about 6000 monographs from NCMC, of which most are outdated and withdrawn from the collection currently (University of Kelaniya, 2008). The staff of the library consists of 15 members. The current library collection consists of about 9000 monographs. It occupies the largest library are available for its users, which is $644.1 \mathrm{~m}^{2}$. The library remains open from 8 a.m. to 7 p.m. on weekdays and 8 a.m. to 6 p.m. on Saturday. It is closed on Sundays and on 
public holidays. The Medical library of University of Kelaniya caters to a population exceeding 1000 students and 102 academic staff members currently (University of Kelaniya, 2008).

The library of the Medical Faculty, University of Sri Jayawardenepura has a history dating back to 1990 . This is the only library assessed under the present study which is located within the main library. It has a collection of about 7500 monographs, and has5 staff members. It occupies an area of $379.9 \mathrm{~m}^{2}$ that is available for its users. (University of Sri Jayawardenepura, 2007). It remains open from 8 a.m. to 6 p.m. on week days and Saturdays during normal academic times, but remains open till 8 p.m. during examination times. Though it is usually closed on Sundays and public holidays, it remains open till 8.00 p.m. on Sundays, public holidays and during examination times. The library caters to a student population of about 1150 and 125 academic staff members.

Collections of medical libraries assessed are maintained in two distinct categories as lending or reference books. The collections comprise of lending or loans (LN) books, scheduled reference (SR) and permanent reference (PR) books. In addition to general permanent reference books, all three libraries assessed contain Sri Lankan collections and WHO collections reserved for inlibrary use. Copies of heavy demand books limited in number are kept for inlibrary use in order to allow maximum usage.

Loan policies among the three libraries considered demonstrated differences in both length of loan period, and in number of documents allowed to be borrowed at a time. SR books are lent for over-night only in all the three libraries. The Medical libraries of UKFM and SJPFM allow borrowing of two LN books and one SR book at a time. The loan policy of the Medical library of UCFM allows borrowing of only one LN book and one SR book at a time. Loan 
policies of Medical libraries of UCFM and UKFM allows lending LN books for a week, and that of SJPFM allows lending of LN books for a period of two weeks.

Observations of this researcher revealed that medical libraries of University of Colombo and Kelaniya followed similar acquisition policies such as purchasing low-priced editions or Indian editions when available. Purchasing low-priced editions has enabled them to acquire a large number of books for a low cost, thereby increasing the copy numbers. The Medical library of University of Sri Jayewardenepura has purchased only the original editions, which were of higher quality print, but relatively expensive. Therefore, copy numbers available for users were limited.

\section{Objectives}

1. To find the usage of library collections of medical libraries of University of Colombo, Kelaniya and Sri Jayawardenepura

2. To suggest measures that could be taken by the three libraries to enhance collection use.

\section{Methodology}

Assessment of material use in the three selected medical libraries, namely (Medical Library of Faculty of Medicine, University of Colombo (UCFM), University of Kelaniya (UKFM) and University of Sri Jayawardenepura (SJPFM)) was carried out in this study using suitable, internationally developed performance indicators.

Indicators developed by three reputed international organizations were considered in selecting indicators for the study. The following publications by the three organizations which provide definitions and information on their 
applicability, methodology for data collections, calculations and analysis were considered for selecting suitable indicators.

1. Measuring quality: performance measurement in libraries.(IFLA Publication 127) (Poll and Boekhorst, 2007), referred hereon as 'IFLA, 2007';

2. ISO 11620: Information and Documentation-Library Performance Indicators (ISO 11620, 1998), referred to hereon as 'ISO 11620, 1998';

3. Measuring Academic Library Performance: A Practical Approach; Chicago: ALA (Van House, and et al, 1990); referred to hereon as 'ALA, 1990'.

The following seven indicators were selected to assess material use in the selected three medical libraries. Selected indicators were arranged under the subcategories; 'use of loan collection', 'In-library use', and 'total material use'.

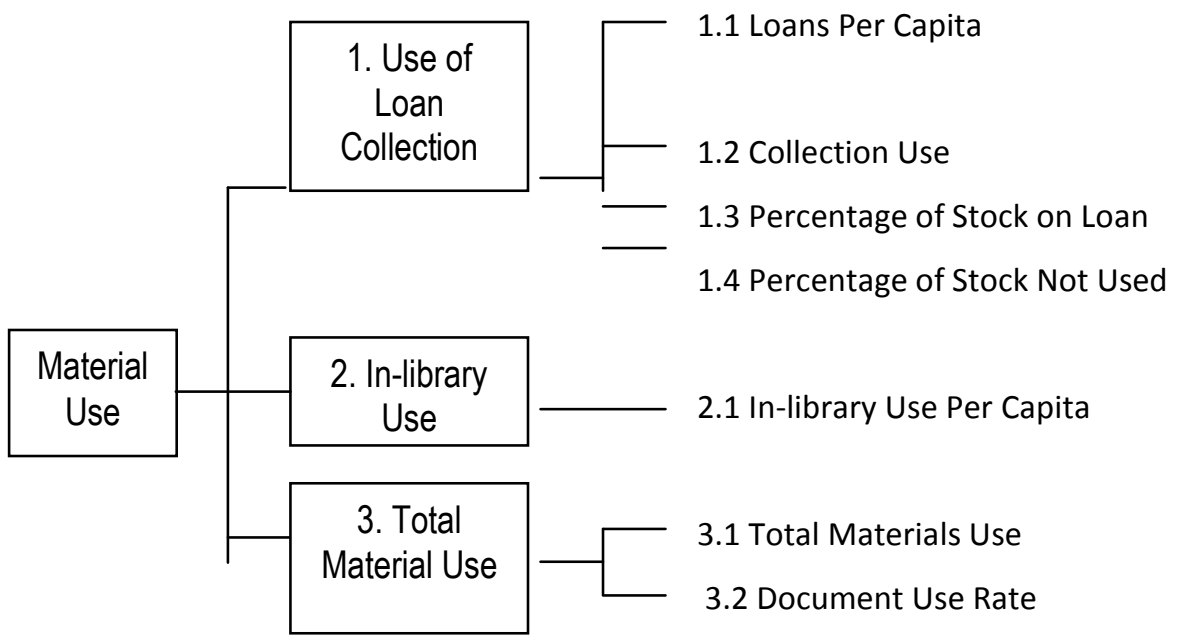

Figure 1: Conceptual Framework for the Present Study 


\section{Use of the Loan Collection}

The use of the collections of materials allowed to be lent were studied in the first section of this study. Loans were considered as lending transactions of physical items to users. New loans and renewals of both LN and SR materials were considered in this study. Interlibrary loans were excluded as books are rarely lent as interlibrary loans. The extent of use of the print lending (LN) collection was assessed using four inter-related indicators.

\subsection{Loans per capita}

This indicator is defined as the average number of books that a single user has borrowed during a year. The total numbers of loans for a specific period (one year) and the total number of registered library users were acquired by library statistics of the libraries under study. Loans per capita values were calculated by dividing the number of loans during a year by the total number of registered users (Poll and Boekhorst, 2007).

\subsection{Collection use}

The indicator can be defined as the total number of loans during a certain period of time (usually one year) as compared to the total number of documents in the loan collection'. Total numbers of loans for a specific period (one year) and total number of documents in loans collections were acquired by library statistics of the libraries under study. The collection use was calculated by dividing the number of loans during a year by the number of documents in the loan collection (Poll and Boekhorst, 2007).

\subsection{Percentage of stock on loan}

The indicator is defined as the number of documents on loan at a specific point of time, expressed as a percentage of the total number of documents in the loan collection'. The total number of documents in the loan collection was established through library statistics. The number of documents that were on 
loan for the sampling days were recorded using the records of automated issuing system or manual counts of issue tickets. The number of documents on loan was calculated as a percentage to total number of materials in loans collections (ISO 11620, 1998).

\subsection{Percentage of stock not used}

This indicator is defined as 'the percentage of documents on the loan collection that have not been used during a certain period of time, usually a year'. "Use" in this indicator means borrowing. For a random sample of LN books in the collection, information on whether a book was issued or not during a certain period of time (usually one year) was obtained by the manual observation of issue slips on books. Documents not available for loan were excluded from the sample (Poll and Boekhorst, 2007).

\section{In-library use}

\subsection{In-library use per capita}

The indicator is defined as 'the number of documents used within the library in a year as a proportion to the population to be served'. For the period of sampling, the number of documents used within the library was estimated using counts of documents left on reading tables before reshelving on sampling days. The population to be served was taken as the total of students and academic staff in the faculty registered in the library. In-library user per capita was calculated by dividing the number of documents used in-house by the total number of registered users (ISO 11620, 1998).

\section{Use of Total Material}

\subsection{Total Material Use}

This self-defined indicator measures the 'total number of uses of library materials of all types'. The definition includes total number of loans and total number of in-library used materials during a year. For calculation of in-library 
use, the number of documents used within the library was counted before reshelving during the sample days and total loans for the same days were calculated. Annual estimates were taken from the counts (Van House, and et al, 1990).

\subsection{Document use rate}

The indicator is defined as 'the percentage of documents owned by the library in use'. The total number of documents on loan on sampling days was acquired by library statistics of the libraries under study. The number of documents being used in-library on the same days was established using the method followed in 2.1: In-library use per capita. 'Document use' included both materials on loan and material used in-library by users on sampling days. The total number of documents in the collection was found using library statistics. Documents used as a percentage to total materials in the library were calculated (ISO 11620, 1998).

\section{Results}

\section{Use of the Loan Collection}

Table 1 - Use of Loan Collection

\begin{tabular}{|c|c|c|c|c|}
\hline Library & Loans Per Capita & $\begin{array}{l}\text { Collection } \\
\text { Use }\end{array}$ & $\begin{array}{l}\text { Percentage of } \\
\text { Stock on Loan }\end{array}$ & $\begin{array}{l}\text { Percentage of } \\
\text { stock not used }\end{array}$ \\
\hline UCFM library & 15.5 & 3.8 & $6.9 \%$ & $23.7 \%$ \\
\hline UKFM library & 20.2 & 5.3 & $7.2 \%$ & $27.0 \%$ \\
\hline SJPFM library & 6.0 & 1.8 & $5.9 \%$ & $31.3 \%$ \\
\hline
\end{tabular}

The study of the extent of use of the print lending (LN) collection was assessed using indicators such as 'loans per capita', 'collection use' and 'percentage of stock on loan'. The highest use of the loans collection is shown by the UKFM 
library and the lowest by the SJPFM library. UCFM library shows an intermediate value in use of the loan collection.

Manual checking of circulation of each book from issue slips or records during a decided time period in the past (a year) of a selected random sample of books revealed that between 23 to 32 percent of books in the loan collection of the three libraries assessed in the present study were not borrowed even once during the year assessed. While the least percentage of non-use was found in UCFM library, the highest percentage was found in SJPFM library with UKFM library falling in between.

\section{In-library Use}

From the results observed, it was evident that users show almost similar rates of in-library use at UCFM and UKFM libraries with a single user borrowing between 55 - 60 documents during a year, but the rate of in-library use in SJPFM library was remarkably low with 38.3. A user at UKFM library has read approximately about 39 more books, a user at UCFM library about 41 more books and a user at SJPFM library 32 more books than he had borrowed during the year, indicating heavy in-library use than borrowing.

Table 2 - In-library Use per Capita

\begin{tabular}{|c|c|}
\hline Library & In-library Use Per Capita * \\
\hline UCFM library & 56.4 \\
\hline UKFM library & 59.2 \\
\hline SJPFM library & 38.3 \\
\hline
\end{tabular}

\section{Use of Total Material}

Both documents borrowed and used in-library on a sample day is assessed here. The total materials use per-capita values gives a better picture for 
comparison. According to results, the difference between per capita values of UKFM library and UCFM library were almost insignificant with the difference of approximately 1 more material used by a user at UKFM library than UCFM library. But users at SJPFM library had shown much less use of materials.

Table 3 - Use of Total Material

\begin{tabular}{|c|c|c|c|}
\hline Library & $\begin{array}{c}\text { Total Materials Use } \\
\text { (in an year) }\end{array}$ & $\begin{array}{c}\text { Total Materials Use } \\
\text { per Capita }\end{array}$ & Document Use Rate \\
\hline UCFM library & 139,346 & 83.2 & $2.2 \%$ \\
\hline UKFM library & 102,432 & 84.6 & $4.0 \%$ \\
\hline SJPFM library & 80,503 & 62.3 & $3.0 \%$ \\
\hline
\end{tabular}

Results showed that UKFM library showed the highest 'document use rate' with $4 \%$ of the total collection been borrowed or used in-library on the sample day. The lowest 'document use rate' was shown by the UCFM library and the intermediate 'document use rate' was shown by SJPFM library.

\section{Discussion}

Assessing the use of loans collection sheds light not only on its use, but also on loans policy and adequacy of the collection to fulfill user needs. Loan policies among the three libraries considered demonstrated differences in both length of loan period, and in number of documents allowed to be borrowed at a time. Loan policy of UCFM library which allows borrowing of only one LN book and one SR book at a time, may have contributed to the low loans collection use when compared to that of UKFM library. The lowest values observed at the SJPFM library indicates poor collection of lending material held at the library. This is further proved by comments of student users of SJPFM library given in a parallel user satisfaction study as 'non-availability of enough titles', 'inadequate number of copies in sufficient numbers', 'inadequate number of 
copies of latest edition' and 'no enough books for borrowing' etc. (Peterson, 2009).

When compared with 'loans per capita' values in international studies, results showed that the values that resulted in all three libraries assessed in the present study are lower than that given in most studies in literature. An average of 58 and 24.1 materials were borrowed by a single user at University libraries in UK (Creaser, Maynard and White, 2006), and in Australia (CAUL, 2007) in 2005 and 2007 respectively. SCONUL statistics show an average 'loans per capita' value of 44 by all university, technical colleges and colleges of higher education libraries in UK in 2008 (SCONUL, 2009). Average 'loans per capita' value observed in Polish university libraries were 8.9 (Derfert-Wolf, Gorski \& Marcinek, 2005).

Low loans per capita values seen in all the libraries assessed under this study can be attributed to facts such as restriction of most new and high demand books for in-house use, unavailability of required titles and inadequate copies for borrowing etc.

Results show compatible degree of loan collection when compared with available literature. Results of collection use for 2004 in 13 participant libraries of the benchmarking project in the Netherlands for the documents acquired to the library during the past two years ranged from 1.9 to 4.9. (UKB, 2004 cited in Poll and Boekhorst, 2007).

The high percentage of non-use (non-borrowing) of lending material indicates that the loan collections may contain both irrelevant and out-dated material. Availability of online information resources contributes to the reduction of borrowing as well. Furthermore, heavy photocopying of material in order to 
possess material for quick and regular reference reduces the rate of borrowing. According the Lancaster (1993), and Poll and Boekhorst (2007), many studies have been carried out to check the patterns of use of library collections. The Pittsburgh study in 1979 which is considered as the most complete study of the topic had revealed that approximately half $(48.37 \%)$ of the collection of the Hilman Library of the University of Pittsburgh was not borrowed at all during the period of 86 months (Kent, 1979 cited in Poll \& Boekhorst, 2007). Collection non-use of the three participating libraries of EQLIPSE project (Evaluation and Quality in Library Performance: System for Europe) ranged from $29 \%$ to $39 \%$ (EQLIPSE, 1997). Compatible or even better results have been attained in the libraries assessed under the present study when compared to results shown in literature.

Although borrowing is considered as the main service offered by libraries with loan collections, the use of material within the library contribute to material use as well. Often a user may refer to more than one material at a time, contributing to high in-house use. High in-library use may suggest poor loans collection. Expanding the loan collection to meet user needs should be considered by all three libraries assessed. Heavy in-library use also suggests greater need for study space, study carrels and chairs, reshelving staff and photocopiers.

Actual results show that the total number of documents in the collection directly influence total material use. Actual values showed that the total number of documents used on the sample day was higher in UCFM than in UKFM library, but due to the larger collection held, 'document use rate' of UCFM library has taken the lowest value. Limitation of user area, available seats and loan policy allowing one item per user at a time to borrow must have contributed to low 'document use rate'. This low usage value, in spite of 
highest user population, should be taken into consideration by the management of the UCFM library and reasons should be analyzed. Also it is advisable to find out whether the majority of the collection is outdated, and a suitable weeding policy should be adopted. According to actual values, the total number of documents used in SJPFM library was considerably low, but small collection size has resulted in a high 'document use rate' at SJPFM library. UKFM library shows highest results with an intermediate size of a collection.

The UKFM library, of which collection and opening hours fall in between comparably, showed the highest usage due to allowing of borrowing two LN books per user at a time and larger user area. Comparably low results of UCFM library as compared UKFM library may be due to inadequacy of seats, small user area and loan policy which allows borrowing of only one LN book by a user at a time at UCFM library. Low collection use of observed at SJPFM library could be attributed to poor collection and short period of opening hours when compared to the other two libraries.

\section{Conclusion}

According to the present study, the highest use of the library collection, in both lending and in-house use, was shown by the UKFM library, followed by the UCFM library. SJPFM library shows the least usage. While the least percentage of non-use of loans collection during the sample year was observed in UCFM library, followed by the UKFM library, the highest percentage of nonuse of loans collection was seen at the SJPFM library. Quality and quantity of the library collection, library opening hours, loans policy and seating capacity within the library may be affecting the use of the library's collection. 


\section{Recommendations Based on the Study}

1. Medical library of University of Sri Jayawardenepura should make immediate measures to amend its collection development policy and increase the quality and quantity of its lending collection.

2. The Medical library of University of Colombo should consider amending its loan policy to increase the number of books allowed to be borrowed by a single user at a time.

3. Increasing the opening hours of the library and opening during Sundays and public holidays is recommended to both libraries of UKFM and SJPFM.

4. Adopting suitable weeding policies can be recommended for all three libraries studied.

5. Proper guidelines should be adopted for acquiring books donated to the library.

\section{References}

CAUL (2007) CAUL online statistics, council of Australian university libraries [online] [accessed $3^{\text {rd }}$ April 2009]. Available on World Wide Web <http://www.anu.edu.au//caul/stats >

Creaser, C., Maynard, S. and White, S. (2006) LISU annual library statistics 2006: featuring trend analysis of UK public and academic libraries 1995-2005, LISU, Loughborough University [Online] \{Accessed $2^{\text {nd }}$ April, 2009]. Available from World Wide

Web:<http://www.lboro.ac.lk/departments/dils/lisu/downloads/als06. pdf $>$

Derfert-Wolf, L., Górski, M. M. and Marcinek, M. (2005) Quality of academic libraries - funding bodies, librarians and users perspective: A common project of Polish research libraries on comparable measures 71th IFLA Council and General Conference August 14-18, 2005 <http://www.ifla.org/IV/ifla71/Programme.htm> [accessed 17 September 2006]

EQLIPSE (1997) Evaluation and quality in library performance: system for Europe (1995-1997) [online] [accessed $31^{\text {st }}$ March 2009]. Available on World Wide Web: <http://www.cerlim.ac.uk/projects/eqlipse/ > 
ISO 11620 (1998) Information and Documentation-Library Performance Indicators. Geneva: International Organization for Standardization

Lancaster, F. W. (1993) If you want to evaluate your library... Illinois: University of Illinois.

Peterson, D. T. (2009) Performance measurement of medical libraries in Sri Lanka: a comparative study. Thesis (Master of Library and Information Science). University of Colombo

Poll, R. and Boekhorst P. te (2007) $2^{\text {nd }}$ edn. Measuring quality: performance measurement in libraries. Müchen, Saur.

SCONUL (2009) SCONUL annual statistics 2007-2008, Society of College, National \& University Libraries, London [Online] Accessed $3^{\text {rd }}$ April 2009]. Available on World Wide Web:<http://www.sconul.ac.uk/statistics/>

University of Colombo (2008) Annual Report, Colombo: University of Colombo.

University of Kelaniya (2008) Library Statistical Profile: Faculty of Medicine, University of Kelaniya (Unpublished).

University of Sri Jayawardenapura (2007) Annual Report. Gangodawilla: University of Sri Jayawardenapura

Van House, N. A., and et al (1990) Measuring Academic Library Performance: A Practical Approach Chicago: ALA 